\title{
Video Maping: oportunidad y uso como dinamizador del turismo cultural en la ciudad de Málaga
}

\author{
Elisa Ogalla Mancheño* José Luis Caro Herrero** Ana Luque Gil*** \\ Universidad de Málaga (España)
}

\begin{abstract}
Resumen: Los edificios con pinturas murales del siglo XVIII en Málaga constituyen uno de los recursos con mayor potencial turístico aún no explotado de los que dispone la ciudad. Proponemos mediante este estudio cómo seleccionar los inmuebles más adecuados según los requerimientos del vídeo mapping y del turismo cultural. Hemos estudiado que metodología se adecua para la labor de la elección del emplazamiento del vídeo mapping. Para ello, se han propuesto una serie de criterios: algunos técnicos, inherente a la tecnología del vídeo mapping, y sobre todo turísticos. Estos últimos basados en la obra de Sust X. (1975) sobre los valores arquitectónicos en el turismo y otros basados en valores que reclama el turista de perfil cultural. Obtuvimos como resultado, tras la aplicación de los criterios diseñados, que solo cinco de los dieciséis inmuebles estudiados cumplían los criterios técnicos y turísticos de forma satisfactoria. Además de una primera aproximación metodológica que ayude a los agentes turísticos con el emplazamiento de esta tecnología para la dinamización cultural de nuestro patrimonio con el vídeo mapping.
\end{abstract}

Palabras Clave: Vídeo mapping; Destino cultural; Pinturas murales.

Video mapping: opportunity and use as a factor to promote cultural tourism in the city of Malaga.

Abstract: Buildings with mural paintings from XVIII century in Malaga represent one of the resources with most tourist potential that the city can offer and are not yet exploited. In this study, we propose how to select the most appropiate buildings according to the requirements of videomapping and cultural tourism. We have studied which methodology is suitable for choosing the location of the videomapping. To this end, a number of criteria have been proposed: some technical and inherent toe Videomapping technology, but most of them tourist. in line with the work of Sust X. (1975) on architectural values in tourism and others based on cultural tourists demands. We concluded that after applying the proposed criteria, only five out of the sixteen buildings included in the study satisfied both technical and tourist criteria satisfactorily. Furthermore, a first methodologic approach to assist tourism agents with location of this technology for the cultural dynamisation of our heritage has been provided.

Keywords: Videomapping; Cultural tourism; Wall painting.

\section{Introducción}

Desde mediados del siglo XX la actividad turística ha tenido un crecimiento exponencial en algunas zonas de España, la Costa del Sol ha sido una de las zonas de mayor importancia. Frente a este avance, la capital malagueña debía definirse en todos los aspectos que conforman un destino turístico, si quería competir y ganar visibilidad en una zona de gran afluencia turística que hasta hace unos años no lograba captar (López I., y Navarro E. 2007). Málaga ha evolucionado mucho como ciudad y como destino turístico desde entonces, y la apuesta principal de la ciudad ha sido definirse como un destino

Postgraduada. Máster en Dirección y Planificación del Turismo. Facultad de Turismo. Universidad de Málaga, España; E-mail: asilee192@hotmail.com

** Profesor Titular del Área de Lenguajes y Sistemas Informáticos. Departamento de Lenguajes y Ciencias de la Computación. Facultad de Turismo. Universidad de Málaga, España; E-mail: jlcaro@uma.es

*** Profesora Titular del Área Análisis Geográfico Regional. Departamento de Geografía. Facultad de Turismo. Universidad de Málaga, España; E-mail: geoana@uma.es 
turístico de calidad apostando por marcas cómo Picasso, Thyssen, Pompidou, etc. En definitiva, hacerse un hueco dentro de la marca de destino turístico cultural, por la que están apostando algunos destinos. El estudio que aquí se presenta va en la dirección de ayudar a Málaga en este desempeño uniendo la tecnología del vídeo mapping y nuestro patrimonio más olvidado: las fachadas pintadas de Málaga.

El turista cuya principal motivación es la cultura, tiene la característica de requerir una información con mayor profundidad y calidad de los elementos que visita, que otro perfil turístico. Esa información no puede presentarse de cualquier forma en destinos que apuestan por la calidad turística. Cada vez más, forma parte del trabajo del destino, agentes privados y públicos, diseñar cuales van a ser los vehículos para difundir la información. Uno de los vehículos que tiene más importancia actualmente, y que en la mayoría de los casos resulta un aliado perfecto para el turismo cultural es la tecnología. Nuestro estudio presenta una propuesta metodológica, a través del diseño de unos criterios técnicos y turísticos, para la elección del emplazamiento del vídeo mapping, para ello hemos tomado como caso de estudio las casas con fachadas policromadas de la ciudad de Málaga.

Los policromados de la ciudad de Málaga, procedentes de la Edad Moderna, se encuentran bien representados en la arquitectura malagueña y son los grandes olvidados desde un punto de vista turístico en la ciudad de Málaga. Estas fachadas pintadas esperan el impulso final que las visibilice tanto para la población como para el turismo, a veces, como en este caso el proceso converge en una misma solución para ambas.

a) Las fachadas pintadas de Málaga en el siglo XVIII.

Este gusto estético por policromar las fachadas de las casas proviene desde la Edad Antigua, y resurge en el Barroco que con su afán decorativo viste las fachadas de los edificios de arquitectura doméstica y civil de una calidad y riqueza extraordinaria. Este fenómeno se ve bien representado en algunas ciudades europeas, especialmente en las italianas y en algunas españolas como Málaga, Granada, Madrid y Cádiz (Asenjo, 2004).

En cuento a la técnica decorativa de la fachada está muy unida a su proceso de construcción, en muchos casos donde no había tradición latericia se utiliza la mampostería. Esta tiene que cubrirse con un "jarado", que suele ser una mezcla de cal, arena o solo yeso que ayude a su preservación. Luego, sobre el jarado se hacían blanqueamientos, recovas o los últimos pulimentos. Se embellece estos recodos con pinturas o esgrafiados. Había diversas técnicas dentro de la pintura policromada, normalmente son frescos y sus motivos más comunes son: geométricos, florales, arquitectónicos, y figurativos. Así mismo se usaba la técnica del esgrafiado, principalmente para los motivos geométricos (Camacho, 1992).

Estas casas pintadas nos aportan una información de un valor incalculable a la hora de trasladarnos a la visión de la arquitectura, gustos plásticos y en algunos casos idiosincrasia de la vida en la Málaga desde la Edad Moderna hasta finales del siglo XVIII. En definitiva, posibilita observar desde nuestro presente ciertos escenarios urbanos ya pasados dotándolos de una nueva significación. Ya que, además, justamente este periodo es el que sale más perjudicado en el ideario urbano que realiza un turista al pasear por Málaga.

Desde la década de los 90 se ha hecho un gran esfuerzo desde las instancias municipales por rehabilitar estos edificios. Actualmente más de una veintena de inmuebles con fachadas pintadas en el centro histórico han sido rehabilitados. Constituyen un bien con suficiente presencia en el entramado urbano y no se justifica que aún no sea parte visible de la imagen del destino. Además, poseen una calidad y riqueza artística excepcionales.

Actualmente estás fachadas pintadas están protegidas a través de los Catálogos de Edificios Protegidos. La Oficina de Rehabilitación del Centro Histórico de Málaga tomó el testigo después de la disolución de El Plan del Color de Málaga 1997. Este último, fue un concurso público que supuso el análisis de más de 1500 fachas de edificios de Málaga, con la que se elaboró una muestra de los colores de las mismas, estado de conservación, elementos de la fachada, etc. y también se llevó a cabo la labor de documentar el patrimonio arquitectónico de Málaga (Romero J., 2008).

Recientemente se ha elaborado, por parte del Ayuntamiento de Málaga unos itinerarios, concretamente tres rutas, entorno a las fachadas pintadas de Málaga que están disponibles para su descarga a cualquier ciudadano. Vemos que, aunque es una excelente idea, ofertarla en inglés o incluirla dentro de la información que se le da al visitante en los puntos de información de la ciudad es el paso siguiente a seguir (Fachadas recuperadas en el centro de Málaga. Itinerarios, 2010).

b) El vídeo mapping.

El vídeo mapping consiste en proyectar imágenes sobre superficies reales, generalmente inanimadas, para conseguir efectos de movimiento o 3D. Suelen ir acompañado de algún tipo de efecto sonoro con 
la finalidad de darle mayor espectacularidad (Catanese, S. 2013). Su uso como reclamo turístico en España es reciente y minoritario, ya que hasta este momento ha sido un espectáculo urbano dirigido a la población. Sus características lo hacen un recurso idóneo para la difusión y recuperación del patrimonio arquitectónico. Esto último es así, ya que al proyectar únicamente luz sobre la fachada, es idóneo para recuperar, aunque sea de forma ilusoria, la pintura mural que se ha perdido en los edificios o informar y difundir este patrimonio recreando otras fachadas con pinturas murales existentes. El que no sean necesarias modificaciones en la fachada para aplicar el vídeo mapping presenta la ventaja de que no hipotecamos un recurso modificándolo permanentemente, sin saber si en un futuro tendremos otros valores de lo que implica una rehabilitación correcta de nuestro patrimonio con pinturas murales.

Esta tecnología puede presentar algunos retos en relación a la protección y conservación de las pinturas murales, como puede ser valorar si afecta negativamente la luz procedente de los proyectores en el espectáculo a las pinturas murales. Esto está aun por estudiar, y siempre sería posible proyectar los motivos pictóricos en el área contigua en el que no se hallan los motivos pictóricos.

Nuestro objetivo es crear un método de análisis sistemático para seleccionar los edificios más idóneos para la implantación del vídeo mapping, cuando la finalidad es de difusión cultural de un bien, para lo que hemos desarrollado unos criterios técnicos y turísticos. Para nuestro objetivo hemos seleccionado como caso de estudio las fachadas pintadas de Málaga. Con las que aplicaremos la metodología propuesta con el fin de conocer las mejores fachadas con pinturas murales, en las que se pueda llevar a cabo video mapping con una finalidad turística cultural y llegar a unas conclusiones sobre nuestra metodología.

El artículo se estructura en los siguientes apartados. En el segundo apartado, realizaremos una valoración del turismo cultural, en el que se analizarán las características propias del mismo; el papel de la tecnología, el perfil turístico y las motivaciones de este perfil turístico. Continuaremos en el apartado tercero, en el que describiremos la metodología desarrollada definiendo un conjunto de criterios técnicos y turísticos para la implantación de vídeo mapping en los bienes inmuebles a los que hemos dirigido estudio. A continuación, en el cuarto apartado presentaremos los resultados de nuestro caso de estudio. En éste se presentan los criterios de selección de las pintadas del centro histórico de Málaga y, aplicando la metodología desarrollada, se examinará cuáles son las apropiadas para la implantación exitosa de un sistema de video mapping. Por último, finalizamos el artículo presentando unas conclusiones y consideraciones finales.

\section{El turismo cultural y las tecnologías para la interpretación y difusión del patrimonio histórico.}

En la actualidad el turismo cultural se ha convertido en la apuesta de muchos destinos turísticos, ese interés tampoco escapa a la comunidad científica, que ha desarrollado en los últimos años una extensa bibliografía. Nos hemos centrado en algunos de los conceptos más importantes asociados al turismo cultural, la conceptualización y problemática de esta tipología turística. Por otra parte, el uso de la tecnología como potenciador e instrumento en los recursos turísticos de tipo patrimonial está a la orden del día y no ha quedado excluido de este proceso de revolución tecnológica digital.

Las tecnologías que más se han aplicado para la interpretación y puesta en valor del patrimonio son muy diversas. Las primeras en aplicarse fueron los Sistemas de Catalogación Informatizados, después llego al área de protección de bienes, con identificadores electrónicos y con la ayuda de los sistemas de catalogación el trabajo pasó a ser mucho más eficaz. En la red ha tenido el patrimonio siempre un lugar destacado, tanto en forma de páginas oficiales que han ido desarrollando todas las instituciones respecto a su patrimonio en el ámbito del turismo, como blogs, redes sociales, portales temáticos etc., en los cuales se pueden encontrar multitud de información. Lo más interesante, es que mucha de la información sobre el patrimonio que se ha generado en la web, ha partido de los usuarios, lo que implica que una gran parte de la población está sensibilizada en el valor del patrimonio, y que es una parte activa de él, al contribuir de algún modo, a su difusión. De hecho, a lo largo de estos años se han creado páginas para defender elementos en peligro, que no estaban bajo una figura legal de protección pero que ciudadanos o un colectivo percibían como importantes (Monerés C, 2012).

En los últimos años se viene desarrollando una serie de tecnología muy interesante para la interpretación y promoción turística como lo son:

a) La reconstrucción digital, que permite reconstrucciones de objetos que se ha perdido o están deteriorados, o componer una imagen en 3D de un elemento (edificio, objeto, sala...) de tal forma que desde un ordenador puedes acceder a él en sus tres dimensiones. 
b) Los códigos QR han sido de gran utilidad a la hora de facilitar información al turista de una forma cómoda para él, y que presenta muchas ventajas respecto al método tradicional y más extendido de información en el patrimonio cultural: los paneles informativos y los folletos.

c) La realidad aumentada consigue crear entornos aumentados con gran realismo, y además junto con la realidad virtual puede incluir cosas que no se han conservado o cualquier otra cosa que se desee. Las posibilidades de difundir y promocionar el patrimonio con esta herramienta son infinitas.

d) El vídeo mapping definido por Guirao Cases. F (Guirao Cases F., García Sánchez g., Folgar Batista K., Brotons Giner M., Ledgard Majidi N., Perruca Jaén I., 2012). "es una técnica que consiste en proyectar imágenes sobre superficies reales, generalmente inanimadas, para conseguir efectos de movimiento o $3 D$ dando lugar a un espectáculo artístico fuera de lo común. Este tipo de espectáculos suele ir acompañado de algún tipo de efecto sonoro". Un buen ejemplo es su uso en las pinturas de las tumbas etruscas de Cerveteri en las que ayuda a resaltar o completar partes que se han perdido de la pintura y además crea un espectáculo visual y sonoro que acompaña al visitante durante la visita a explicando las tumbas ${ }^{1}$. En España, en la mayor parte de los casos, se ha usado puntualmente sobre edificios emblemáticos para la ciudadanía con el fin de crear un espectáculo en unas fechas determinadas. Buenos ejemplos de ello son; los vídeo mapping realizados en la ciudad de Sevilla, cada año, en la época navideña en diversos edificios emblemático de la ciudad, Barcelona ha llevado a cabo espectáculos de video mapping en edificios tan emblemáticos como la Sagrada Familia, la casa Batló, y el ayuntamiento, en Santiago de Compostela para la celebración de los Fuegos del Apóstol, en el año 2011 y 2016, en el año jubilar en 2012 en El Rocío, y en el $4^{\circ}$ centenario de la Plaza Mayor en Madrid en el año 2017. En la siguiente imagen podemos ver uno de los momentos del espectáculo de Video Mapping en la Catedral de Santiago de Compostela en el año 2012.

\section{Ilustración 1: Espectáculo de Video Mapping en la Catedral de Santiago en el año 2012.}

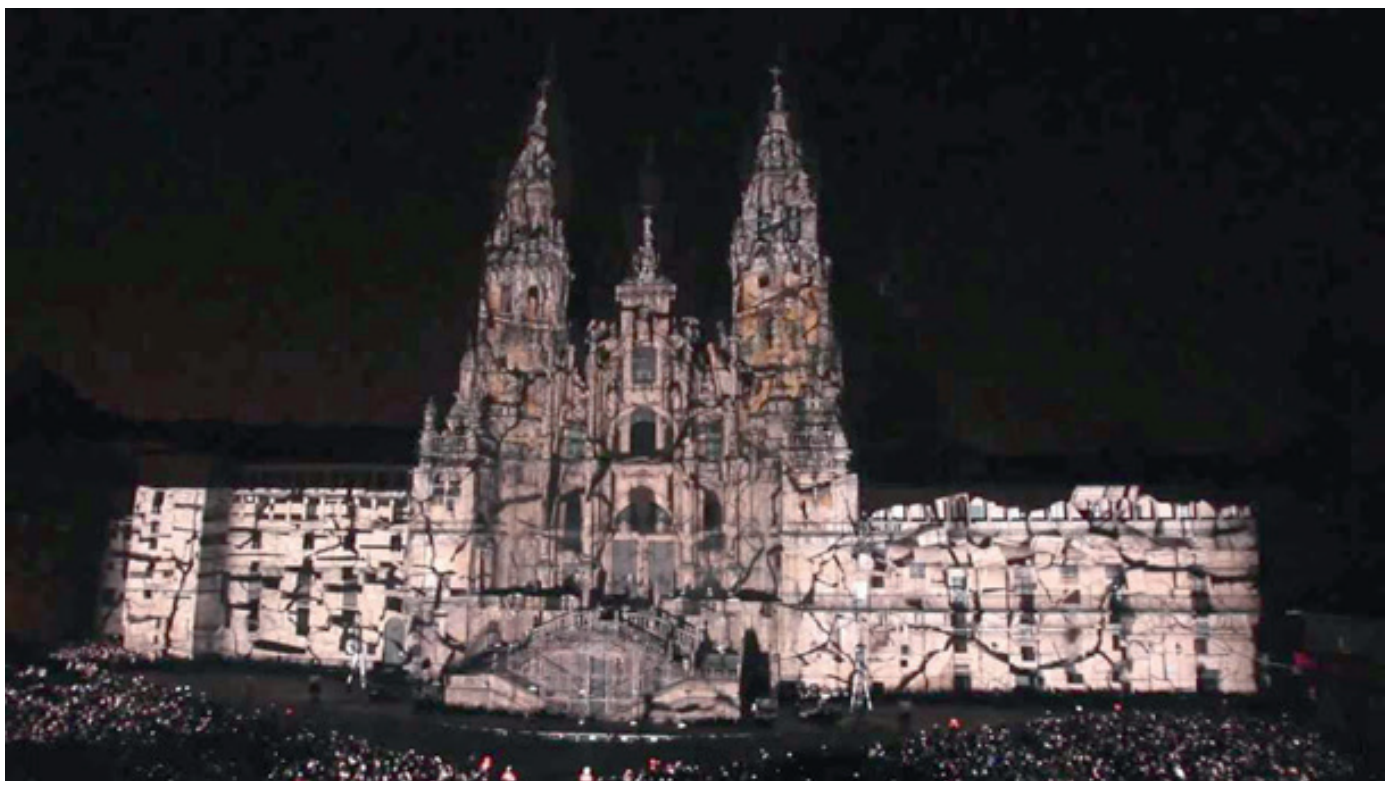

Fuente: Acciona Producciones y Diseño, 2012.

Los destinos turísticos en su configuración del turismo cultural a través de la explotación de su patrimonio deben tener en cuenta si reúne las condiciones para ser viable desde un punto de vista turístico. La viabilidad turística del patrimonio es definida por Prats (2011) desde tres grandes posibilidades: 1) recursos de gran entidad, capaces de atraer por sí mismos una cantidad de visitantes suficiente para justificar la ubicación de infraestructuras turísticas, 2) recursos patrimoniales con una capacidad menor 
de atracción, pero que se hallan situados en centros de ciudades importantes o en las cercanías y 3) recursos patrimoniales de destinos turísticos consolidados.

El mercado turístico ha ido creando nuevos productos, entre ellos el turismo cultural. Es decir, una serie de productos cuyo nexo común gira en torno a la cultura, y la cultura vivida desde la experiencia. Cuando hablamos de turismo de experiencia nos referimos a que se asume que existe una dimensión; se refiere a la dimensión psicológica y afectiva del turismo. Algunos autores en el área de la investigación del turismo cultural defienden que este no es solo es una experiencia sino también una emoción (Cluzeau, 2000; Duran, 2002; Vidal, 2002; Richards, 2006) lo que lo dota de una cualidad altamente subjetiva.

El creciente aumento del turismo cultural está relacionado con la importancia que le da la sociedad al valor de la cultura. Nos movemos en un marco conceptual de sociedades post-industriales, por tanto no solo se consumen bienes materiales, sino también servicios, entre otras finalidades con la de distinguirse. Una de las formas de llevar esto a cabo es mediante la adquisición de la cultura, cómo símbolo de status. Ya hemos dicho, que se tiende a preferir formas no materiales de consumo en áreas como el turismo, debido a esto el crecimiento de las experiencias dentro de los productos turísticos y el éxito de los productos relacionados con la cultura.

El turismo cultural tiene otra cualidad, no menos interesante, y es su capacidad creativa (Richards, 2001; Greffe, 2002; de Cluzeau, 2002; Donaire, 2002) dado el diálogo que se establece entre lo antiguo y lo nuevo. Richards presenta una idea ya discutida por Urry, y lo cita para explicar el cambio que ha habido en el turista cultural, más lejos cada vez de una mirada pasiva, y que se convierte a la vez en consumidor y productor de su propia experiencia cultural en el destino (Richards 2001). En esta misma línea algunos autores como Geffe (2002) apuntan a que el turista busca con su viaje cultural dar un nuevo sentido a sus interacciones sociales.

Tal y como hemos dicho la creatividad es la piedra angular que todo destino cultural que quiera ser puntero y competitivo a medio-largo plazo debe tener en cuenta. Una de las vías para canalizar esa creatividad es a través de la interacción con el público. Se trata de ofrecer la información no sólo de una forma pedagógica sino también sorprendente, de tal forma que contribuya a crear una experiencia. Es en este punto, donde la tecnología del Vídeo mapping resulta un gran aliado, tanto por novedosa como por su gran espectacularidad.

La Carta Internacional sobre Turismo Cultural (ICOMOS, 1999) plantea un controvertido problema relacionado con el turismo cultural y el patrimonio de cada comunidad, que se encuentran ante el reto de la necesidad de preservar el recurso y a la vez comunicar de forma efectiva su significado al turista $o$ visitante. Ante esta realidad, muchas veces se generan tensiones entre los intereses que el turismo persigue y la necesidad de protección de los recursos culturales ante el impacto turístico que estos provocan en él. En determinados casos como el que nosotros planteamos aquí, la solución viene de la mano de la tecnología, reduciendo parte del impacto que recibe el recurso que queremos poner en valor desde un punto de vista turístico. Estas diferencias de intereses entre el sector cultural y turístico, se ven muy bien reflejadas en Mckercher y du Cros (2002) y las presento aquí sintetizadas en un cuadro:

\section{Tabla 1: Diferencia entre el sector cultural y turístico en la consideración del patrimonio.}

\begin{tabular}{|l|l|l|}
\hline & \multicolumn{1}{|c|}{ Sector Cultural } & \multicolumn{1}{c|}{ Sector Turístico } \\
\hline Actores & Sector público y sector terciario & Sector privado \\
\hline Finalidad & Búsqueda de beneficios sociales & $\begin{array}{l}\text { Búsqueda de beneficios } \\
\text { económicos }\end{array}$ \\
\hline Actividad de gestión básica & Proteger y difundir el bien & Comercializarlo \\
\hline Valores atribuidos & Valor simbólico & Valor de uso \\
\hline Destinatarios & Población & Turista \\
\hline Motivación & Aprender, disfrutar, intelectual & Ocio \\
\hline $\begin{array}{l}\text { Principales atracciones de los } \\
\text { bienes }\end{array}$ & $\begin{array}{l}\text { Valor cultural, la belleza, y la } \\
\text { singularidad }\end{array}$ & $\begin{array}{l}\text { Prestigio, comodidad, distancia, } \\
\text { tiempo }\end{array}$ \\
\hline
\end{tabular}

Fuente: Elaboración propia en base a Mckercher y du Cros (2002). 


\section{Metodología para la selección de fachadas de inmuebles de interés patrimonial para la realización de vídeo mapping}

En el proceso de investigación se siguen unos pasos marcados por Weaver y Oppermann (2000) con la finalidad de seguir un proceso metódico y lógico que pueda arrojar resultados veraces y de valor. Para este trabajo se ha optado por una metodología cualitativa que, como ya sabemos, se fundamenta en la realidad, tiene carácter exploratorio, descriptivo e inductivo. Concretamente realizaremos un estudio de caso. Para ello vamos a explicar los criterios elaborados que luego aplicaremos a nuestro estudio de caso. A continuación vemos un cuadro-resumen con los criterios definidos y el desarrollo pormenorizado de cada uno de ellos.

\section{Ilustración 2: Criterios de selección propuestos para el video mapping en fachadas de interes patrimonial}

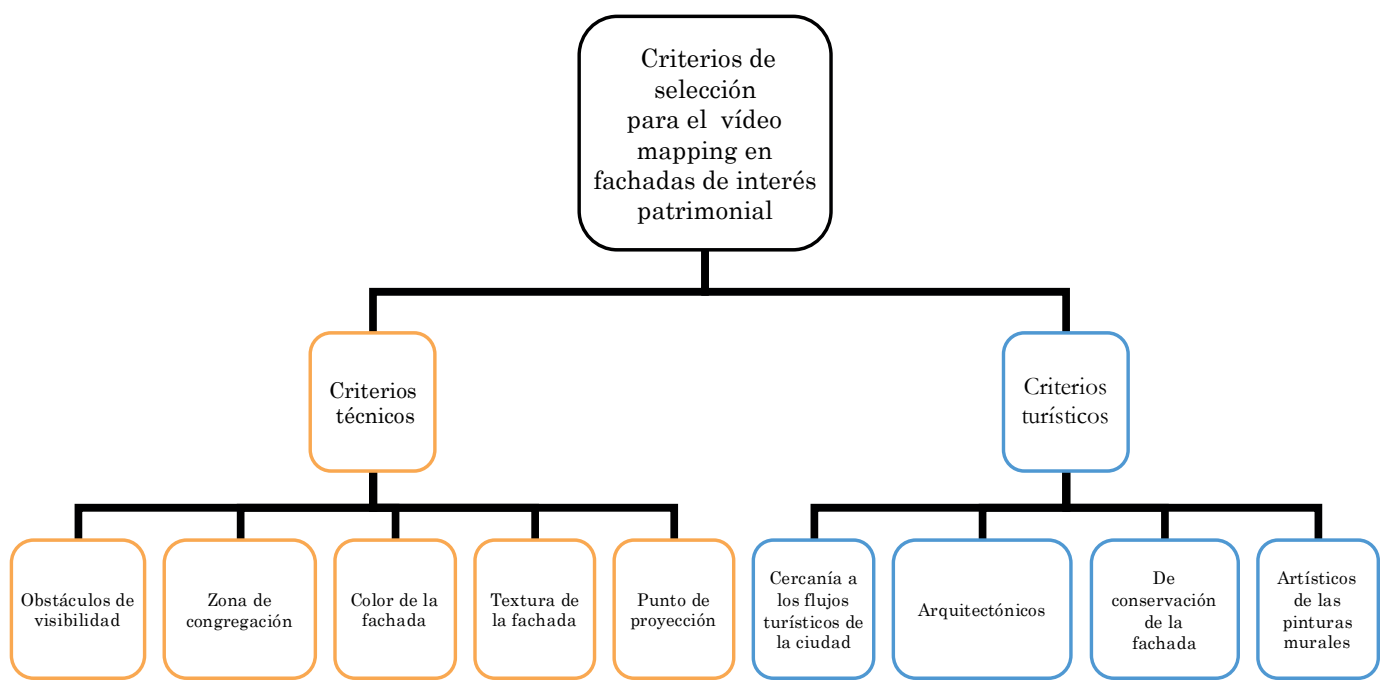

\subsection{Criterios técnicos.}

A la hora de elaborar un espectáculo de vídeo mapping se tienen en cuenta diversos aspectos (Valero, E. 2012), nosotros los vamos a agrupar según el momento en el que se den en el proceso de producción del espectáculo. Primero la preproducción, que incluye la localización, el levantamiento, la conceptualización, las necesidades y los recursos. Segundo la producción, que engloba la animación-video, el equipo, el mapeo y la proyección.

En este trabajo sobre todo nos centraremos en describir los aspectos que comprenden a la preproducción del espectáculo, ya que es ahí donde se concentran todos los aspectos a tener en cuenta desde un punto de vista técnico en la localización del vídeo mapping.

La preproducción comprende la localización y el levantamiento de la fachada. En la localización encontramos todos los factores que van a constituir nuestros criterios técnicos de elección del emplazamiento. Ya que es uno de los puntos más cruciales para el éxito del vídeo mapping. A continuación, presentamos qué factores reúne la localización y lo criterios que hemos extraído de estos.

a) Los obstáculos que pueden estar entre el edificio y el lugar donde estarán los proyectores, y que pueden intervenir en la proyección.

b) Examen de la zona de congregación, en la que se estudiará la visibilidad, el aforo, y el ángulo de proyección adecuado para el proyector.

c) La estructura del edificio, en cuanto a si es redondo, cuadrado, curvo, las ventanas, balcones, columnas, líneas y aristas representativas. Determina la dificultad posterior en el mapeo de la fachada.

d) El color de la fachada, será muy importante para determinar el brillo de la animación. La dificultad será mayor cuánto más oscuro sea el color que predomina en la fachada. Además, no 
solo se recogerá el color de la fachada en general, sino también de forma detallada las zonas en las que se conserve la pintura mural.

e) La textura de la fachada y el material del que está hecho la fachada intervendrán a la hora de absorber la luz, de la intensidad con la que se refleje el color proyectado, y la nitidez de la proyección. Las fachadas irregulares o deterioradas son una mala opción para realizar en ellas esta técnica.

f) La iluminación artificial que hay en esa calle, ya que de esta dependerá la cantidad de lumens necesarios en los proyectores. Cuanta más luz artificial haya en la calle, mayor cantidad de lumens son necesarios en los proyectores. Estos tienen un precio más elevado y puede ser necesario un mayor número de proyectores.

g) Punto de protección, es el lugar donde se van a situar los proyectores. Depende de varios factores como el ángulo de proyección, este viene dado por la distancia desde el punto de proyección a la fachada y la altura dónde se vaya a situar el proyector. Esto determinará el número de proyectores necesarios junto con el tamaño de la fachada.

Según el punto de proyección se elegirá el tipo de lentes que usará el proyector, ya que determina si espacio de proyección es más amplio o cerrado.

Únicamente para nuestro estudio hemos atendido a los criterios derivados de la localización porque son los que guardan una estrecha relación sobre la idoneidad de una fachada para el uso de esta tecnología. Os presentamos aquí la relación de criterios técnicos:

1) Obstáculos de visibilidad: Se examinará si existen en ese momento obstáculos que impedirían o dificultarían la proyección. Son los que se encuentran entre el posible punto de proyección y la fachada en la que se va a realizar la proyección.

2) Zona de congregación: Este criterio es el más subjetivo, porque depende del número de personas que quieran que visualicen por sesión del espectáculo. Hemos establecido que se valora positivamente las calles o plazas que tengan más de dos metros y medio en la anchura de calle frente a la fachada. No es un espacio para grandes congregaciones de público pero es con el fin de no excluir a gran parte de los edificios que se encuentren en calles de trazado antiguo. Además, como aquí lo presentamos como un recurso establecido de forma permanente en la ciudad. Su demanda habitual, tras la visualización de la mayor parte de la ciudadanía interesada, serán los turistas con lo que el público potencial se reduce y equilibra en relación al espacio.

3) Color de la fachada: Se recoge el color predominante en cada fachada, es decir el color que comprendía una mayor área. Los colores oscuros influirán negativamente en la calidad y en los lúmenes necesarios para proyectar en esa fachada.

4) Textura de la fachada: Se recoge la textura de la fachada y se divide en lisa, positiva para la proyección e irregular, valorada negativamente.

5) Punto de proyección: entraremos a valorar únicamente si existe punto de proyección, hallando la distancia mínima que se necesita para tener una amplitud de proyección de al menos un metro de ancho para limitar de esta forma el número de proyectores necesarios. Se calcula mediante una fórmula matemática.

Teniendo también en cuenta que para tener un ángulo de proyección hace falta una distancia mínima del proyector al punto de proyección para que la imagen de la proyección tenga la amplitud suficiente para abarcar una fachada.

Siguiendo con los factores de preproducción, vamos a describir brevemente lo que conciernen al levantamiento de la fachada. Consiste en la toma de medidas de diversos aspectos que influyen en el mapeo de la fachada y la proyección. Para las medidas se utiliza un medidor laser, o de ultrasonido, aplicaciones en dispositivos móviles específicas como son Planimeter o Camera Rule. Estas medidas ayudarán a determinar algunos aspectos clave para la proyección, y son estas principalmente:

a) Los proyectores que se necesitarán, según la altura del edificio si se va a realizar el vídeo mapping en toda su extensión, si es en diversas caras del edificio, o si los ángulos en los que hay que situar los proyectores impiden cubrir toda la proyección con un solo aparato.

b) Las medidas del "lienzo" en el que se desarrollará la proyección.

c) La distancia desde la fachada hasta donde se colocarán los proyectores.

d) La altura dónde se colocarán los proyectores

e) El área de congregación recomendada para no perder el ángulo de proyección. 
La digitalización de la facha del edificio, con la finalidad de tener las medidas precisas del mismo lo ideal es contar con los planos de este. En el caso de no tener acceso a ellos, bastará con tomar las medidas y hacerlos con un programa como AutoCad o similar.

Tomar las medidas exactas del edificio da una gran ventaja a la hora de garantizar que el contenido del vídeo mapping se plasme conforme a la estructura de la fachada y no haya que realizar muchas modificaciones a la hora de probar y calibrar los proyectores.

A partir de los planos, se procede a la digitalización de los mismos para crear la animación con un modelado 3D de la fachada. Con este modelado se pueden hacer pruebas digitales de ajuste de contenido audiovisual, teniendo en cuenta la distancia y posicionamiento de los proyectores y otros factores.

\subsection{Criterios turísticos}

Con la finalidad de que este recurso se incorpore a la oferta turística de la ciudad se valoraran una serie de factores que facilitan y posibilitan que un bien patrimonial se convierta en un recurso turístico. Estas consideraciones de diversa índole, debidamente justificadas, serán nuestros criterios turísticos a partir de categorías conceptuales consolidadas en el mundo del arte y el turismo. Estos se aplicarán en el estudio de cada caso con el patrimonio que corresponda. Los criterios turísticos que desarrollamos son estos: criterios de localización, criterios arquitectónicos, criterios de conservación y criterios artísticos.

La localización de un recurso turístico es un factor que ayuda o dificulta el flujo de visitantes que capta el recurso debido a que la lejanía de este a los principales flujos turísticos de la ciudad es un factor de penalización en la intención de visita. Por eso mismo, el primer criterio establecido es la cercanía a los flujos turísticos de la ciudad, ya que sin ser el vídeo mapping un atractivo turístico consolidado ni ampliamente conocido, valoramos que es necesaria su cercanía a los principales flujos turísticos de la ciudad, a no ser que el recurso al que se le va aplicar el vídeo mapping sea un atractivo turístico de la ciudad. Mediremos la cercanía, en el tiempo empleado en el desplazamiento a pie desde cualquiera de las calles de mayor flujo turístico al recurso que proponemos. Estableceremos un máximo de 10 minutos para considerar que un recurso cumple este criterio.

La arquitectura, cuando hablamos de bienes patrimoniales muebles, incluye una serie de valores que no solo son percibidos por el turista sino apreciados por él. Por tanto, hemos incluido todos los factores intervinientes para la valoración arquitectónica de un inmueble por parte de los turistas. Nos hemos basado en los estudios de Sust (Sust. X, 1975) y Zamudio (Zamudio Vega. L.S, 2012) sobre los valores arquitectónicos en el turismo. Hemos establecido un total de 11 valores que constituyen el criterio arquitectónico:

a) Singularidad puntual

Focalización en partes específicas del edificio sin valorar la construcción por su conjunto.

b) Decoración

Interés en las pinturas, mosaicos, retablos, etc. del edificio sobre todo si son de una calidad sobresalientes.

c) Contenido (arquitectura como museo)

El edificio se menciona por lo que contiene, pero sus características pasan a un segundo plano.

d) La anécdota

El edificio es relevante por lo que ha ocurrido en él.

e) Antigüedad

Es un factor importante para el turismo, la antigüedad es un valor consolidado.

f) Alardes constructivos

Hay un valor que destaca por su complejidad, rareza, dimensiones...

g) Nobleza

El origen noble de un edificio lo hace más atractivo para los turistas.

h) Tamaño y grandiosidad

Su tamaño llama la atención en relación con el uso del edificio, tiene unas dimensiones excepcionales.

i) Pintoresquismo

Resalta una idea romántica del pasado. 
j) Rareza formal

Dentro de un orden o un estilo arquitectónico tiene variaciones que lo hacen especial.

k) Entorno urbano y paisajístico

El edificio cobra relevancia por su contexto urbano o natural.

El estado de conservación del edificio, es otro de nuestros criterios y está íntimamente relacionado con la valoración arquitectónica del bien. Hemos preferido individualizarlo dada su importancia para el turista y por la dificultad de darle un peso relativo dentro de un criterio arquitectónico con tantos valores como hemos considerado. Las valoraciones en este criterio tienen la calificación de deficiente, para los edificios en el que el deterioro de la fachada y de los elementos arquitectónicos de la misma, impiden o dificultan la apreciación artística de las mismas y de la arquitectura del edificio. La calificación de bueno, muy bueno y excelente gradúan cuantitativamente desperfectos menores que en ningún caso impiden la valoración de las pinturas murales ni de la arquitectura global del edificio.

La calidad artística, es el único criterio exclusivo de nuestro caso de estudio. Todas las fachadas pintadas que vamos a incluir en nuestro estudio están restauradas, pero en no todas se han podido recuperar la totalidad de las pinturas $u$ otros factores que influyen en la calidad final que percibe el turista, por lo que la observación directa de las pinturas a sido uno de los medios utilizados. También valoramos la calidad artística propiamente dicha, y para ello nos hemos ayudado de el estudio pormenorizado que hace de ellas Asenjo (2008), ya que el turista también valora la belleza y singularidad pictórica de estas pinturas.

Por tanto, hemos realizado una valoración global que incluye la calidad artística y a través de la observación directa hemos penalizado a las que por múltiples causas, relacionadas directamente con las pinturas, la calidad que percibe turista se ve mermada. Las valoraciones serán deficiente, a las que la calidad artística haya sido valorada negativamente por lo expertos, luego será; buena, muy buena y excelente y la graduación dependerá de cuánto menor número de factores relacionados con la conservación o la integridad de las pinturas le afecten negativamente y la valoración artística recogida principalmente en la bibliografía señalada.

\section{Aplicación de la metodología para una selección de fachadas pintadas de Málaga y sus resultados.}

Para nuestro caso de estudio nos hemos basado en una selección de fachadas pintadas previa que ya realizó Asenjo (Asenjo E, 1999). Esta primera selección consta de los inmuebles en mejor estado de conservación en el centro histórico y pertenece a una ruta turística de fachadas pintadas propuesta por Asenjo (Asenjo. E, 2004). Esta selección de fachadas pintadas están divididas por su localización en las zonas del Centro, ciudad extramuros, y la Victoria. Es la que mostramos a continuación (tabla 2).

\section{Tabla 2: Rutas por las fachadas con pinturas murales de Málaga propuestas por Asenjo en su artículo "En torno a las posibilidades culturales de las fachadas pintadas en Málaga: un patrimonio Emergente".}

\begin{tabular}{|l|l|l|}
\hline \multicolumn{1}{|c|}{ Zona del centro } & \multicolumn{1}{|c|}{ La ciudad extramuros } & \multicolumn{1}{c|}{ La Victoria } \\
\hline Alameda Principal & Calle de la Serna & Santuario de la Victoria \\
Calle Nueva & Pasillo de Santo Domingo & Capilla de San Lázaro \\
San Juan & Nosquera & \\
Hornos & Nuño Gómez & \\
Plaza de la Constitución & Gaona & \\
Fresca & Parras & \\
Santa María & & \\
San Agustín & & \\
Tomás de Cózar & & \\
Virgen de las penas & & \\
\hline
\end{tabular}

(Asenjo E. 2004). 


\subsection{Aplicación de criterios turísticos para la elección de fachadas pintadas de Málaga para la realización del vídeo mapping.}

a) Criterios de cercanía a los flujos turísticos

Para identificar los flujos turísticos de la ciudad de Málaga hemos recurrido al trabajo de García en el que se detallan con exhaustividad (García. S, 2013). Como ya dijimos se valora positivamente la cercanía a estos, y establecimos un máximo de 10 minutos de desplazamiento desde los principales flujos de la ciudad a el recurso como límite a partir del cual quedaría excluido ese inmueble.

Hemos medido los tiempos a los que se sitúan la primera selección de fachadas de las calles con transito turístico medio-alto. Las que se encuentren a más de 10 minutos se excluirán, por los motivos ya explicados.

\section{Tabla 3: Fachadas pintadas de Málaga según su cercanía a zonas de gran tránsito turístico.}

\begin{tabular}{|c|c|c|}
\hline $\begin{array}{l}\text { Calles de Málaga con flujo } \\
\text { alto-medio de turistas }\end{array}$ & $\begin{array}{c}\text { Fachadas }<10 \text { minutos a } \\
\text { pie de alguna de las calles } \\
\text { anteriores }\end{array}$ & $\begin{array}{c}\text { Fachadas }>10 \text { minutos a } \\
\text { pie de alguna de las calles } \\
\text { anteriores }\end{array}$ \\
\hline $\begin{array}{l}\text { Plaza de la Merced } \\
\text { Plaza de la Marina } \\
\text { Paseo del Parque } \\
\text { Cervantes } \\
\text { Granada } \\
\text { San Agustín } \\
\text { Marqués de Larios }\end{array}$ & $\begin{array}{l}\text { Calle Nueva }{ }^{\circ} 11 \\
\text { Calle San Juan } n^{\circ} 9 \\
\text { Calle Hornos }{ }^{\circ} 12 \\
\text { Plaza de la Constitución } n^{\circ} 13 \\
\text { Plaza de la Constitución } n^{\circ} 15 \\
\text { Plaza de la Constitución } n^{\circ} 7 \\
\text { Calle Fresca n } 8 \\
\text { Calle Tomás de Cózar } n^{\circ} 13 \\
\text { Calle Torregorda n }{ }^{\circ} 3 \\
\text { Plaza Virgen María de las Penas } \\
n^{\circ} 4 \\
\text { Calle Granada } n^{\circ} 80 \\
\text { Calle Beatas n }{ }^{\circ} 35 \\
\text { Alameda Principal n }{ }^{\circ} 11 \\
\text { Calle Granada } n^{\circ} 12 \\
\text { Calle Granada } n^{\circ} 50 \\
\text { Calle Atarazana } n^{\circ} 11\end{array}$ & $\begin{array}{l}\text { Calle Serna } \\
\text { Pasillo de Santo Domingo } \\
\text { Calle Nosquera } \\
\text { Nuño Gómez } \\
\text { Gaona } \\
\text { Parras }\end{array}$ \\
\hline
\end{tabular}

Fuente: Elaboración propia.

Como vemos, se han excluido tres fachadas de la selección inicial del artículo de Asenjo (Asenjo. E, 2004), que cumplían los requisitos de estar a menos de 10 minutos andando de alguna de las calles con más afluencia turística, estas son: las situadas en la calle Santa María, por su estado de conservación y la de calle San Agustín que al tratarse de una Iglesia que se encuentra en un recinto cerrado y no se observan con claridad las pinturas desde el exterior.

A su vez, se han incluido ocho fachadas nuevas; las de calle Torregorda, Plaza María de las Penas, calle Beatas, Calle Atarazana, Plaza de la Constitución n ${ }^{\circ} 15$, Plaza de la Constitución $n^{\circ} 17$, Calle Granada $\mathrm{n}^{\circ} 12$ y Calle Granada ${ }^{\circ} 50$. Esto decisión ha sido motivada por su cercanía a las zonas de alto tránsito turístico, el buen estado de conservación de sus pinturas y que a priori no está justificado excluirlas de nuestra investigación, aunque no apareciesen en nuestra selección de referencia.

Han quedado a más de 10 minutos de cualquiera de las calles de medio alto tránsito de turistas todos los inmuebles que estaban en la selección previa clasificadas como fachadas en zonas de extramuros. Estas no seguiremos analizándolas con el resto de criterios. Podemos ver en la siguiente imagen la localización de cada uno de los inmuebles que finalmente hemos seleccionado para realizar el estudio. 
Ilustración 3: Localización de los inmuebles seleccionados para el estudio.

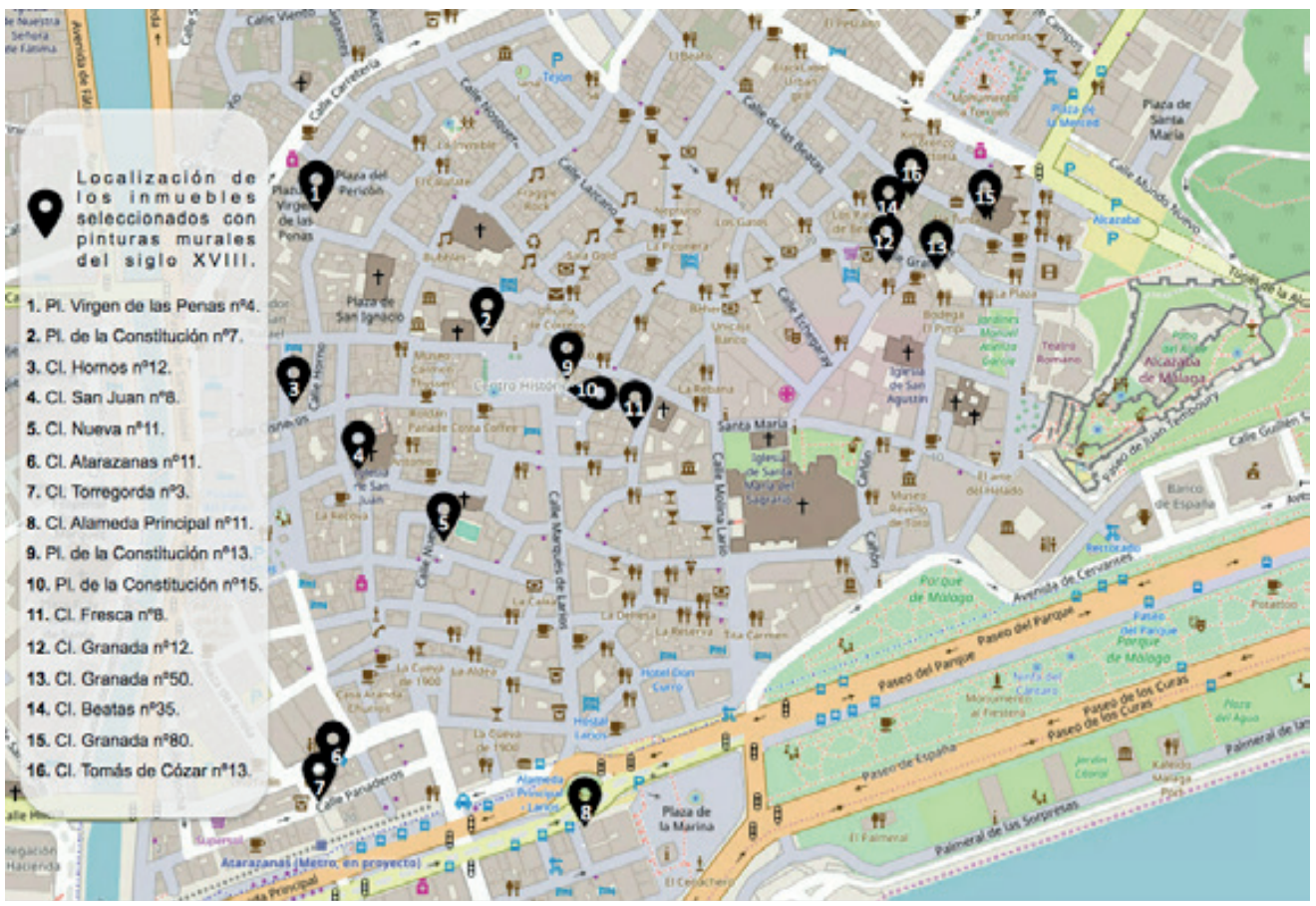

Fuente: elaboración propia a partir de openstreemaps (s.f)

b) Criterios de conservación de la fachada del edificio

\section{Tabla 4: Resultados de los criterios de conservación de la selección de casas pintadas de Málaga.}

\begin{tabular}{|c|c|}
\hline Localización & Estado de conservación de la fachada \\
\hline Plaza Virgen de las Penas n ${ }^{\circ} 4$ & Muy bueno, restaurada \\
\hline Calle San Juan n ${ }^{\circ} 8$ & Muy bueno, restaurada \\
\hline Calle Hornos $\mathrm{n}^{\circ} 12$ & Excelente, restaurada \\
\hline Plaza de la Constitución nº 13 & Muy bueno, restaurada \\
\hline Plaza de la Constitución $n^{\circ} 15$ & Muy bueno, restaurada \\
\hline Plaza de la Constitución $n^{\circ} 7$ & Bueno, restaurada \\
\hline Calle Atarazanas $\mathrm{n}^{\circ} 11$ & Excelente, restaurada \\
\hline Calle Fresca $n^{\circ} 8$ & Muy bueno, restaurada \\
\hline Calle Torregorda $\mathrm{n}^{\circ} 3$ & Muy bueno, restaurada \\
\hline Calle Tomás de Cózar n ${ }^{\circ} 13$ & Bueno, restaurada \\
\hline Calle Beatas n ${ }^{\circ} 35$ & Excelente, restaurada \\
\hline Calle Nueva ${ }^{\circ} 11$ & Excelente, restaurada \\
\hline Calle Granada n ${ }^{\circ} 80$ & Muy bueno, restaurada \\
\hline Calle Granada n ${ }^{\circ} 12$ & Muy Bueno, restaurada \\
\hline Calle Granada n ${ }^{\circ} 50$ & Excelente, restaurada \\
\hline Calle Alameda Principal n ${ }^{\circ} 11$ & Excelente, restaurada \\
\hline
\end{tabular}

Fuente: Elaboración propia. 
c) Criterios artísticos de las pinturas murales

Tabla 5: Resultado de los criterios artísticos de la selección de casas pintadas de Málaga.

\begin{tabular}{|c|c|c|}
\hline Localización & Singularidad & Calidad Técnica \\
\hline Plaza Virgen de las Penas nº 4 & & Buena \\
\hline Calle San Juan n ${ }^{\circ} 8$ & $\begin{array}{l}\text { Su pintura pertenece a tres momentos } \\
\text { distintos del Barroco }\end{array}$ & Muy buena \\
\hline Calle Hornos n ${ }^{\circ} 12$ & & Muy buena \\
\hline Plaza de la Constitución nº 13 & & Muy buena \\
\hline Plaza de la Constitución n ${ }^{\circ} 15$ & $\begin{array}{l}\text { La decoración se realiza con ladrillos cocidos } \\
\text { formando series geométricas entorno a las } \\
\text { cornisas }\end{array}$ & Muy buena \\
\hline Plaza de la Constitución $\mathrm{n}^{\circ} 7$ & & Muy buena \\
\hline Calle Atarazanas n ${ }^{\circ} 11$ & & Excelente \\
\hline Calle Fresca ${ }^{\circ} 8$ & & Excelente \\
\hline Calle Torregorda $\mathrm{n}^{\circ} 3$ & $\begin{array}{l}\mathrm{Si} \text {, no se atiene a los motivos decorativos } \\
\text { del periodo. Sus motivos son exóticos con } \\
\text { escenas de América como tiendas de indios y } \\
\text { una serpiente de mar }\end{array}$ & Excelente \\
\hline Calle Tomás de Cózar nº 13 & & Buena \\
\hline Calle Beatas n ${ }^{\circ} 35$ & & Excelente \\
\hline Calle Nueva ${ }^{\circ} 11$ & & Muy buena \\
\hline Calle Granada n ${ }^{\circ} 80$ & & Muy buena \\
\hline Calle Granada n ${ }^{\circ} 12$ & & Buena \\
\hline Calle Granada n ${ }^{0} 7$ & & Excelente \\
\hline Calle Alameda Principal n ${ }^{\circ} 11$ & & Excelente \\
\hline
\end{tabular}

Fuente: Elaboración propia. 
c) Criterios arquitectónicos

Tabla 6: Resultado de los criterios arquitectónicos de la selección de casas pintadas de Málaga.

\begin{tabular}{|c|c|c|c|c|c|c|c|c|c|c|c|c|c|c|c|c|}
\hline & 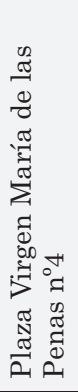 & 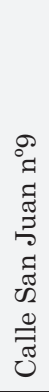 & 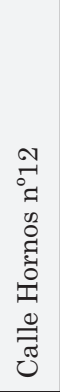 & 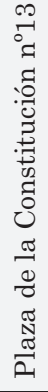 & 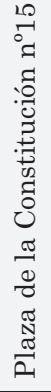 & 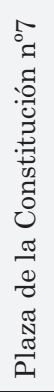 & 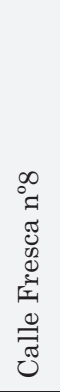 & 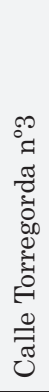 & 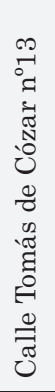 & 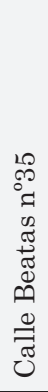 & 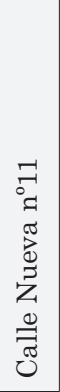 & 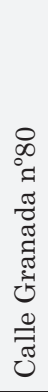 & 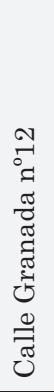 & 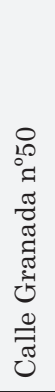 & 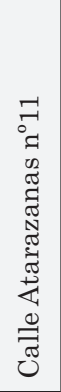 & 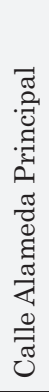 \\
\hline $\begin{array}{l}\text { Singularidad } \\
\text { Puntual }\end{array}$ & No & $\mathrm{Si}$ & No & $\mathrm{Si}$ & $\mathrm{Si}$ & No & No & No & No & No & No & $\mathrm{Si}$ & No & No & No & No \\
\hline Decoración & $\mathrm{Si}$ & $\mathrm{Si}$ & $\mathrm{Si}$ & $\mathrm{Si}$ & $\mathrm{Si}$ & $\mathrm{Si}$ & $\mathrm{Si}$ & $\mathrm{Si}$ & SI & $\mathrm{Si}$ & $\mathrm{Si}$ & $\mathrm{Si}$ & $\mathrm{Si}$ & $\mathrm{Si}$ & $\mathrm{Si}$ & $\mathrm{Si}$ \\
\hline $\begin{array}{l}\text { Contenido } \\
\text { (arquitectura } \\
\text { como museo) }\end{array}$ & No & $\mathrm{Si}$ & No & No & No & $\mathrm{Si}$ & No & No & $\mathrm{Si}$ & No & $\mathrm{Si}$ & $\mathrm{Si}$ & No & $\mathrm{Si}$ & No & $\mathrm{Si}$ \\
\hline La anécdota & No & No & $\mathrm{Si}$ & No & No & No & No & $\mathrm{Si}$ & No & No & No & $\mathrm{Si}$ & No & $\mathrm{Si}$ & No & No \\
\hline Antigüedad & $\mathrm{Si}$ & $\mathrm{Si}$ & $\mathrm{Si}$ & $\mathrm{Si}$ & $\mathrm{Si}$ & $\mathrm{Si}$ & $\mathrm{Si}$ & $\mathrm{Si}$ & $\mathrm{Si}$ & $\mathrm{Si}$ & $\mathrm{Si}$ & $\mathrm{Si}$ & $\mathrm{Si}$ & $\mathrm{Si}$ & $\mathrm{Si}$ & $\mathrm{Si}$ \\
\hline $\begin{array}{l}\text { Alardes } \\
\text { constructivos }\end{array}$ & $\mathrm{Si}$ & $\mathrm{Si}$ & No & $\mathrm{Si}$ & No & $\mathrm{Si}$ & $\mathrm{Si}$ & $\mathrm{Si}$ & No & $\mathrm{Si}$ & No & $\mathrm{Si}$ & No & No & $\mathrm{Si}$ & $\mathrm{Si}$ \\
\hline Nobleza & & & No & & No & $\mathrm{Si}$ & $\mathrm{Si}$ & $\mathrm{Si}$ & No & $\mathrm{Si}$ & No & $\mathrm{Si}$ & No & No & $\mathrm{Si}$ & $\mathrm{Si}$ \\
\hline $\begin{array}{l}\text { Tamaño o } \\
\text { grandiosidad }\end{array}$ & $\mathrm{Si}$ & $\mathrm{Si}$ & No & $\mathrm{Si}$ & No & $\mathrm{Si}$ & $\mathrm{Si}$ & $\mathrm{Si}$ & No & $\mathrm{Si}$ & $\mathrm{Si}$ & $\mathrm{Si}$ & $\mathrm{Si}$ & No & $\mathrm{Si}$ & $\mathrm{Si}$ \\
\hline Pintoresquismo & No & No & No & No & No & No & No & No & No & No & No & No & No & No & No & No \\
\hline Rareza formal & No & $\mathrm{Si}$ & No & $\mathrm{Si}$ & $\mathrm{Si}$ & No & No & No & No & No & No & No & No & No & No & No \\
\hline $\begin{array}{l}\text { Belleza del } \\
\text { Entorno urbano } \\
\text { o paisajístico }\end{array}$ & $\mathrm{Si}$ & $\mathrm{Si}$ & No & $\mathrm{Si}$ & $\mathrm{Si}$ & $\mathrm{Si}$ & No & $\mathrm{Si}$ & No & No & $\mathrm{Si}$ & $\mathrm{Si}$ & No & $\mathrm{Si}$ & $\mathrm{Si}$ & $\mathrm{Si}$ \\
\hline
\end{tabular}

Fuente: Elaboración propia.

\subsection{Aplicación de criterios técnicos para la elección de fachadas pintadas de Málaga para la realización del vídeo mapping.}

Ha sido necesario desplazarse a cada una de las localizaciones de cada inmueble para la recogida de datos que componen los criterios técnicos. Hemos reflejado los resultados en estas tablas (tabla 7). Con el fin de documentar los datos aquí recogidos se han realizado fotografías individualizadas de la fachada y del entorno de cada edificio. Han sido necesarias algunas mediciones para establecer en qué inmuebles, según la anchura de la calle, el punto de proyección es suficiente como para proyectar la fachada completa con el menor número de proyectores posible. Hemos establecido que dos metros y medio es el mínimo, según la fórmula en la que el factor de proyección viene dado por la distancia entre el proyector y la pantalla dividido el ancho de la pantalla. En este caso el ancho de la pantalla es el edificio, la superficie que queramos proyectar de él. Además por debajo de esta medida a penas se visualiza con comodidad la fachada del edificio por parte del espectador y la zona de congregación sería muy limitada. Para realizar estas mediciones hemos utilizado un medidor láser cuyo alcance máximo eran los 16 metros. 


\section{Tabla 7: Resultados de la selección de los criterios técnicos de videomapping para las casas pintadas de Málaga.}

\begin{tabular}{|c|c|c|c|c|c|}
\hline \multicolumn{6}{|c|}{$\begin{array}{c}\text { Criterios técnicos relacionados con el Video mapping para la } \\
\text { elección la fachada con pinturas murales }\end{array}$} \\
\hline Localización & $\begin{array}{l}\text { Obstáculos } \\
\text { para la } \\
\text { visibilidad }\end{array}$ & $\begin{array}{l}\text { Zona de } \\
\text { congregación } \\
\text { de público }\end{array}$ & $\begin{array}{l}\text { Color de la } \\
\text { fachada }\end{array}$ & $\begin{array}{l}\text { Textura de } \\
\text { la fachada }\end{array}$ & Punto de proyección \\
\hline $\begin{array}{l}\text { Plaza Virgen de las } \\
\text { Penas } n^{\circ} 4\end{array}$ & No & $\mathrm{Si}$ & Beige & Lisa & $\mathrm{Si},>16$ metros. \\
\hline Calle San Juan n ${ }^{\circ} 9$ & No & $\mathrm{Si}$ & $\begin{array}{l}\text { Beige, rojo } \\
\text { y amarillo }\end{array}$ & Lisa & $\mathrm{Si},>16$ metros \\
\hline Calle Hornos $\mathrm{n}^{\circ} 12$ & $\mathrm{Si}$ & No & Rojo & Irregular & No, 2,32metros \\
\hline $\begin{array}{l}\text { Plaza de la } \\
\text { Constitución n }{ }^{\circ} 13\end{array}$ & No & $\mathrm{Si}$ & Rojo & Irregular & $\begin{array}{l}\mathrm{Si},>16 \mathrm{~m} \\
\text { (posibilidad de proyectar con } \\
\text { una instalación específica } \\
\text { enfrente) }\end{array}$ \\
\hline $\begin{array}{l}\text { Plaza de la } \\
\text { Constitución n }{ }^{\circ} 15\end{array}$ & No & $\mathrm{Si}$ & Rojo & Irregular & $\begin{array}{l}\mathrm{Si},>16 \mathrm{~m} \\
\text { (posibilidad de proyectar con } \\
\text { una instalación específica } \\
\text { enfrente) }\end{array}$ \\
\hline $\begin{array}{l}\text { Plaza de la } \\
\text { Constitución n }{ }^{\circ} 7\end{array}$ & No & $\mathrm{Si}$ & Beige & Liso & $\begin{array}{l}\mathrm{Si},>16 \mathrm{~m} \\
\text { (posibilidad de proyectar con } \\
\text { una instalación específica } \\
\text { enfrente) }\end{array}$ \\
\hline Calle Fresca n ${ }^{\circ} 8$ & $\mathrm{Si}$ & No & Beige & Liso & No, 2,32 metros \\
\hline $\begin{array}{l}\text { Calle Torregorda } \\
n^{\circ} 3\end{array}$ & No & No & Amarillo & Lisa & $\begin{array}{l}\mathrm{Si},>16 \text { metros } \\
\text { (posibilidad de proyectar con } \\
\text { una instalación específica } \\
\text { enfrente) }\end{array}$ \\
\hline $\begin{array}{l}\text { Tomás de Cózar } \\
\mathrm{n}^{0} 13\end{array}$ & No & $\mathrm{Si}$ & Beige & Lisa & $\mathrm{Si}, 3$ metros \\
\hline Calle Beatas n ${ }^{\circ} 35$ & No & $\mathrm{Si}$ & Beige & Lisa & $\mathrm{Si}, 4$ metros \\
\hline Calle Nueva ${ }^{\circ} 11$ & No & No & Rojo & Rugosa & $\mathrm{Si}, 12$ metros \\
\hline $\begin{array}{l}\text { Calle Alameda } \\
\text { Principal n }{ }^{\circ} 11\end{array}$ & No & $\mathrm{Si}$ & Beige & Lisa & $\begin{array}{l}\mathrm{Si},>16 \text { metros } \\
\text { (posibilidad de proyectar con } \\
\text { una instalación específica } \\
\text { enfrente) }\end{array}$ \\
\hline Calle Granada n ${ }^{\circ} 80$ & No & $\mathrm{Si}$ & Amarillo & Lisa & $\mathrm{Si}>16$ metros \\
\hline Calle Granada n ${ }^{\circ} 12$ & No & No & Beige & Lisa & $\mathrm{Si}, 8$ metros \\
\hline Calle Granada nº50 & No & No & Roja & Rugosa & $\mathrm{Si}, 8$ metros \\
\hline $\begin{array}{l}\text { Calle Atarazana } \\
n^{\circ} 11\end{array}$ & No & $\mathrm{Si}$ & Blanco & Lisa & $\begin{array}{l}\mathrm{Si},>16 \text { metros (posibilidad de } \\
\text { proyectar con una instalación } \\
\text { específica enfrente) }\end{array}$ \\
\hline
\end{tabular}

\section{Resultados y selección final de las fachadas pintadas de Málaga para la proyección de videomapping.}

Se han evaluado un total de dieciséis fachadas, de las cuales seis presentan unas características que han llevado a no considerarlas las más adecuadas para la proyección en estas del video mapping, en base a los resultados que hemos obtenido tras la aplicación de los criterios que hemos definido en este trabajo. 
Presentamos aquí la relación de las fachadas, que tras nuestro estudio nos lleva a considerarlas menos idóneas para nuestro objetivo, algunas han sido agrupadas porque presentan la misma casuística:

- Fachadas con elementos técnicos para la elaboración del vídeo mapping muy desfavorables: Este es el caso de los inmuebles de las calles Hornos, Nueva y Plaza de la Constitución n 13 , Plaza de la Constitución 15 y Calle Granada 12 que debido a la textura y color de las fachadas no son las más adecuadas para la proyección en ellas.

- El inmueble de calle Fresca, al igual que el de calle Hornos, no presenta la calle la suficiente anchura para la visualización correcta del mismo. Apenas dos metros de anchura tiene la calle en las mediciones que se han realizado, imposibilitando la proyección de toda la fachada.

- El inmueble de la calle Tomás de Cózar, presenta las pinturas en peor estado de conservación de la selección y además el entorno urbano se encuentra muy deteriorado.

- El inmueble de calle San Juan y calle Granada ${ }^{\circ} 80$, no presentan una arquitectura en su fachada en la que se pueda proyectar con realismo el fenómeno de las casas pintadas porque no pertenecen a arquitecturas domésticas. Poder dar a conocer el fenómeno de las pinturas murales en la arquitectura doméstica nos parece uno de los motivos por el cual elegir esta tecnología, por tanto, aunque el edificio sea de gran belleza y cumpla los requisitos técnicos limitaría dar a conocer el fenómeno de forma efectiva.

- El inmueble ubicado en calle Beatas y calle Granada n 50 , destaca por su buen estado de conservación tanto del inmueble como de las pinturas, y por la arquitectura de su fachada, con su rejería del siglo XVIII. La calidad técnica de las pinturas es excelente pero el espacio para la congregación de público es insuficiente y el ángulo de proyección para la fachada completa no es posible.

El resto de los inmuebles, cinco en total, poseen cada uno de ellos características distintas, que lo hacen a cada uno de ellos más idóneos, según el tipo de vídeo mapping que se quiera realizar, es decir, según el discurso y orientación que tuviese la propuesta final en el caso de llevarse a cabo el vídeo mapping. Se explicará a continuación porque se ha concluido que estos cuatro inmuebles poseen características que los hacen idóneos bajo nuestros criterios para la realización del vídeo mapping.

- El inmueble ubicado en la Plaza Virgen de las Penas, cumple todos los requisitos técnicos y destaca por un inmejorable lugar de agregación para el público, una gran plaza peatonalizada, en un entorno cuidado y de bajo tránsito peatonal. Destaca también por el estado de conservación del inmueble, tanto por su arquitectura de su fachada, con una rejería del siglo XVIII como por la nobleza del edificio. Todo esto lo configuran como un inmueble con un enorme potencial como soporte didáctico a través del cual, poder conocer el resto de casas pintadas que hay en Málaga, y la arquitectura doméstica.

\section{Ilustración 4: Fachada del inmueble ubicado en la Plaza Virgen de las Penas.}

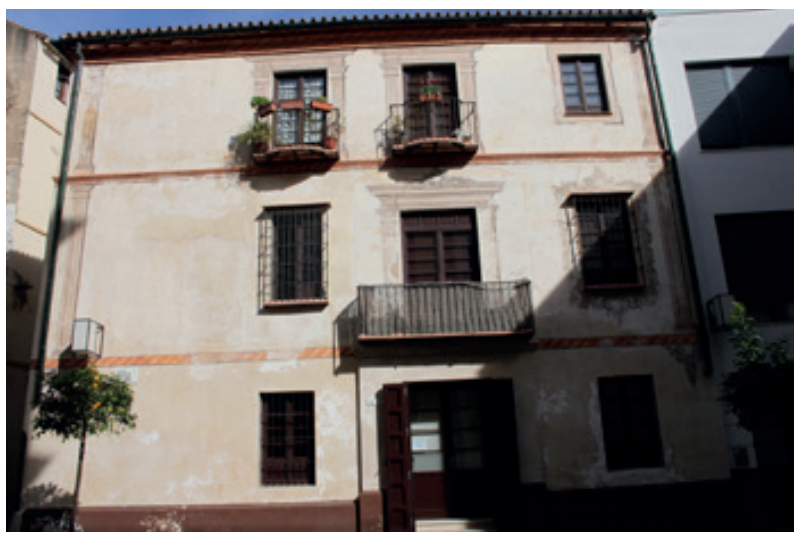

Fuente: elaboración propia. 
- El inmueble ubicado en calle Torregorda, cumple con los requisitos esenciales excepto con el de presentar una zona de congregación adecuada, ya que el público se tendría que situar en la calle Alameda Principal, una de las principales arterías de la ciudad que además no está peatonalizada, por tanto, el lugar de congregación estaría compartido con los transeúntes. Además, está posibilidad solo estaría hasta la construcción del solar que se encuentra paralelo a la casa. Este ha sido seleccionado debido a su singularidad, tanto histórica como formal lo cual sería un gran atractivo a la hora de realizar un video mapping y quizás la posibilidad de habilitar por parte del ayuntamiento una zona de congregación específica en el solar que se sitúa justo enfrente de la fachada orientada a la calle Alameda Principal.

\section{Ilustración 5: Fachada del inmueble ubicado en calle Torregorda.}

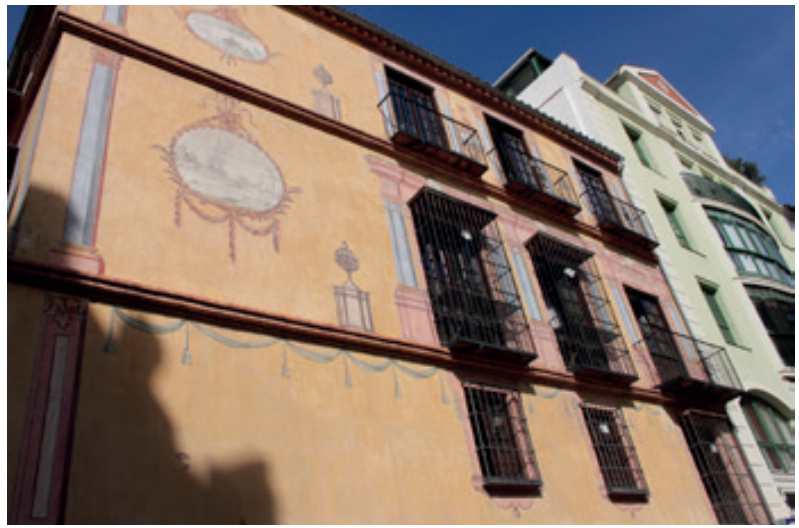

Fuente: elaboración propia.

- El inmueble ubicado en calle Atarazanas, con pinturas de elementos geométrico y que emulan elementos arquitectónicos con una excelente calidad técnica, unido a la nobleza del inmueble y al estado de conservación del mismo, lo convierten en uno de los edificios idóneos para la proyección de vídeo mapping. La dificultad en este caso reside en la zona de congregación que tendría que situarse en la calle de enfrente, una calle transitada y que no permite grandes congregaciones de público.

Ilustración 6: Fachada del inmueble ubicado en calle Atarazana.

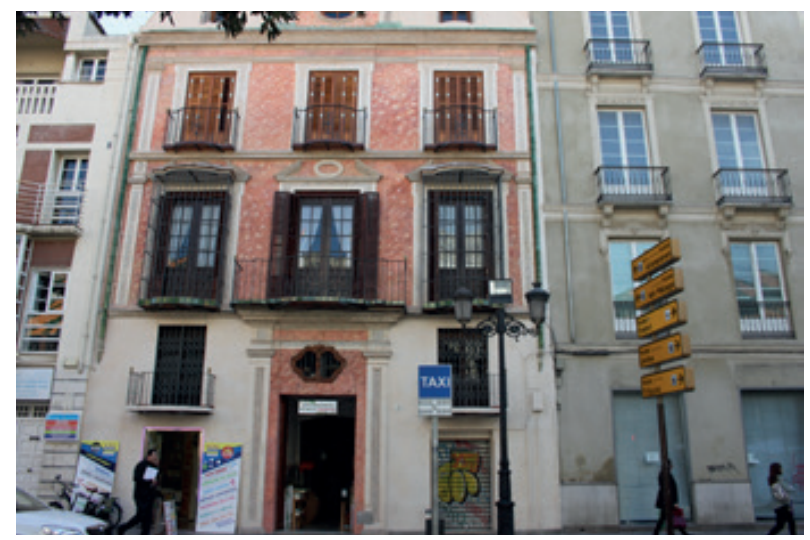

Fuente: elaboración propia. 
- El inmueble ubicado en calle Alameda Principal, con una decoración de excelente calidad técnica y artística basada en columnas y pilastras de arquitecturas fingidas, decoran las dos primeras plantas de este edificio. La posibilidad de congregación enfrente del edificio, en una zona de poco tránsito y lo suficientemente amplia, junto con que el edificio no está destinado a viviendas residenciales lo convierten en una de las mejores opciones para el video mapping.

\section{Ilustración 7: Fachada del inmueble ubicado en calle Alameda Principal.}

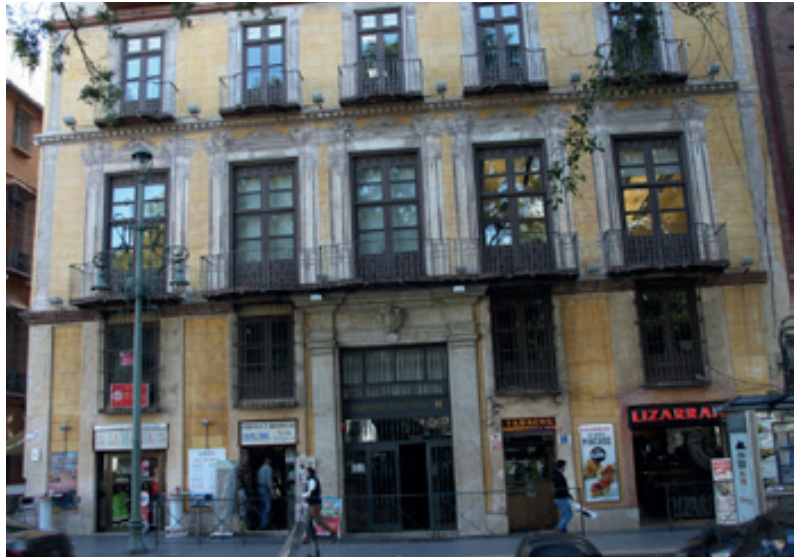

Fuente: elaboración propia.

- El inmueble ubicado en Plaza de la Constitución nº 7, declarado Monumento Arquitectónico y Artístico e incluido en el Catalogo General de Bienes Inmuebles del Patrimonio Histórico Andaluz, es además la Sociedad de Amigos del País. El edificio es de estilo barroco clasicista, con la peculiaridad de ser un edificio-balcón, por la disposición de sus balconadas con una tribuna para los personajes ilustres. Las decoraciones en este caso son esgrafiados menos para los elementos vegetales. Si bien es cierto, que la ausencia de color en las decoraciones de este inmueble lo hacen a priori menos espectacular para el turista. Esto es una desventaja salvable con el vídeo mapping, además son muchas otras las características positivas de este inmueble para realizar un vídeo mapping en él. Es una zona de congregación inmejorable, en una plaza peatonal en una de las zonas más turísticas de la ciudad, el inmueble no está destinado a viviendas habitacionales, y guarda íntegramente la estructura de las arquitecturas domésticas del periodo al que pertenece.

\section{Ilustración 8: Fachada del inmueble ubicado en laPlaza de la Constitución.}

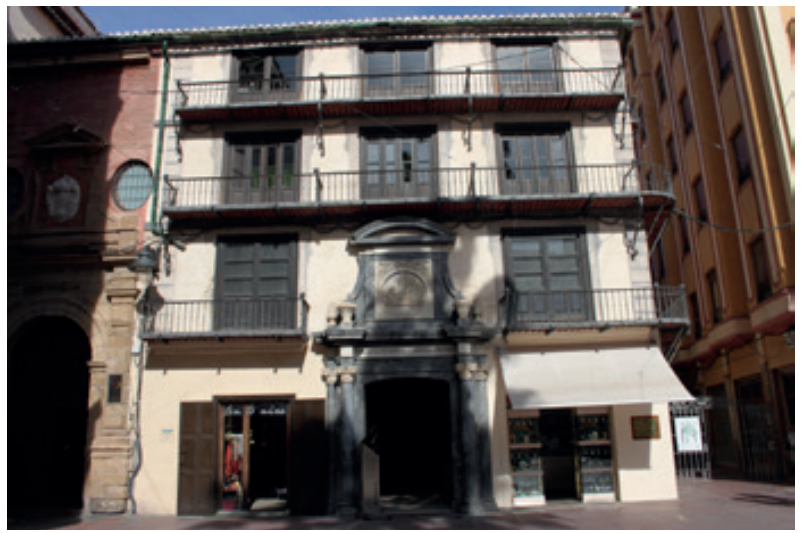

Fuente: elaboración propia. 


\section{Conclusiones e implicaciones}

En la presente investigación se propone una metodología, a través del estudio de una serie de criterios, técnicos y turísticos, con el fin de seleccionar fachadas de edificios de interés artístico-arquitectónico en el que se quieran implementar técnicas de vídeo mapping con un aprovechamiento turístico. En este caso, y con esta metodología hemos estudiado las fachadas pintadas del Barroco que más se adecuasen con la implantación de la tecnología del vídeo mapping, siempre teniendo en cuenta de que lo que se pretende es difundir de forma efectiva el patrimonio de las pinturas murales el siglo XVIII. Se ha llevado a cabo parte de este trabajo con la observación directa de los inmuebles, y la recogida de datos: fotografías, datos técnicos como las medidas de anchura de las calles y localización de las mismas. Concluimos que la sistematización a través de los criterios propuestos a la hora de la elección de las fachadas con la finalidad aquí descrita, favorece la calidad turística del destino ya que permite valorar en cada caso el potencial turístico de cada recurso recogiendo a su vez las especificidades del bien, como en este caso han sido la valoración artística de las pinturas murales.

Hemos recogido y analizado 16 inmuebles en el casco histórico antiguo, con pinturas murales pertenecientes al siglo XVIII. Estas, como hemos visto, en un estado de conservación de bueno a excelente y a menos de diez minutos de las calles más transitadas por los turistas. Por tanto, ponemos en evidencia que es un recurso que tiene suficiente presencia en la ciudad de Málaga como para apostar por su promoción y difusión.

El resultado de esta propuesta es que de los dieciséis inmuebles que hemos estudiado, solo cinco se adecuan de forma satisfactoria, respecto a los criterios propuestos. Estos son los situados en las calles Torregorda, Atarazana, Plaza Virgen de las Penas, Plaza de la Constitución n ${ }^{\circ} 7$ y Alameda Principal. Los dos últimos no solo cumplen todos los requisitos, sino que al no estar destinados actualmente a viviendas los convierten en los edificios más idóneos, ya que salvan los inconvenientes que se producirían de la aplicación continuada en el tiempo de esta tecnología a los habitantes de estos inmuebles.

Cada uno presenta una serie de ventajas y unas características peculiares explicadas ya en los resultados de nuestra propuesta, la elección de la realización en cualquiera de estos cinco inmuebles dependerá más de la orientación concreta; discursiva o práctica, tal y como ya hemos hecho referencia, a que el edificio no se encuentre destinado a viviendas para salvar los posibles inconvenientes.

La apuesta por el turismo cultural en Málaga se está desarrollando con gran rapidez y se ha materializado mayormente en una apuesta museística de un carácter atomizado. Esto es debido a que si bien otras ciudades andaluzas, competencia directa nuestra, tienen una larga tradición patrimonial, Málaga ha intentado posicionarse ante esa realidad con una oferta cultural diversa de nueva creación más que en erigirse en una ciudad monumental. Pero se ha olvidado del rico patrimonio de arquitectura doméstica de los siglos XVIII y XIX, que posee y que confiere al casco histórico una imagen muy peculiar y atractiva para un turista que se ve sumergido en un espacio cuyas calles y edificios le muestran grandes vestigios de una ciudad del pasado. En esta línea se sitúa nuestra propuesta de hacer que las casas pintadas del siglo XVIII sean un recurso turístico con la ayuda del vídeo mapping.

Potenciando este patrimonio, de la arquitectura doméstica barroca y las pinturas murales de sus fachadas, se puede construirse un imaginario turístico propio del destino que sea un factor diferenciador, tanto con el resto de ciudades andaluzas que poseen otro tipo de patrimonio como con el resto de destinos, haciéndonos más competitivos. Lo bueno de apostar por características intrínsecas al destino, como es el patrimonio mueble que ya posee, es que en muchos casos como este, son rasgos distintivos e irreproducibles.

Otra observación fruto de nuestro estudio, es el escaso uso en la ciudad de Málaga de la tecnología para interpretar el patrimonio. Por el momento, los avances se han dirigido a la difusión de la oferta de la ciudad gracias a aplicaciones móviles y audioguías incluidas en estas. Llevar a cabo el uso del vídeo mapping en Málaga sería positivo debido a lo novedoso de esta tecnología, lo cual potenciaría la imagen de Málaga como un destino innovador y de calidad. Siendo uno de los objetivos de Málaga potenciar el turismo de calidad, no se puede obviar la proyección exterior que obtendría Málaga implantando el vídeo mapping de forma permanente, sobre este recurso concretamente, con la intención de atraer a turistas de perfil cultural.

Se ha desarrollado un movimiento ciudadano, expresado en numerosos portales webs que recogen el apoyo a la conservación, rehabilitación y difusión de este patrimonio que está en peligro. Este movimiento se encuentra inmerso en otro mayor que es la reclamación y defensa de parte de la ciudadanía, de los edificios históricos del centro de Málaga. A mediados del siglo XX, se contabilizaban más de 1200 edificios históricos en la ciudad, actualmente quedan casi la mitad. 
Para poder ofrecer un nuevo recurso turístico, con el esfuerzo que requiere por parte de todos los agentes de un destino, es necesario que sea valorado por el conjunto de su ciudadanía. Vemos en este movimiento ciudadano el germen necesario para considerarla parte del patrimonio que debemos apostar por recuperar. Recuperar el patrimonio no es solo rehabilitar estas fachadas, como está sucediendo actualmente, sino si es conveniente hacer un uso plural de las mismas, este puede ser turístico, como hemos propuesto en este trabajo. Aplicar vídeo mapping en estas no solo enriquecería la oferta turística de la ciudad, especialmente en el ámbito cultural, sino que también se harían visibles para otra buena parte de la ciudadanía. Siendo conscientes de que esto último, la valoración del conjunto de la población, es el mejor camino para la conservación de cualquier bien, y además es lo que lo dota de sentido. Solo así, se llegan a constituir atractivos turísticos sólidos y con recorrido en un destino turístico.

\section{Bibliografia}

Acciona.

2012. Espectáculo de Video Mapping en la Catedral de Santiago en el año 2012.. [imagen]. Recuperado el 31 Jul. 2017, de: https://www.youtube.com/watch?v=uWi44jKQUjc .

Asenjo Rubio, E, Lanzas Burgos, J.

1999. Las arquitecturas pintadas del Barroco de Málaga. Cd-Rom Multimedia, Boletín de Arte $\mathrm{n}^{\circ} 20$, Málaga.

2004. En torno a las posibilidades culturales de las fachadas pintadas en Málaga: un patrimonio emergente. Baetica 24: 7-26.

2008. Urbs Picta. El legado cultural de las arquitecturas pintadas de Málaga. Málaga: Servicios de publicaciones de la Universidad de Málaga.

Camacho, R.

1992-1993. Cuando Málaga no era blanca. La arquitectura pintada del siglo XVIII, Boletín de Arte ${ }^{\circ}$ 13-14: $143-170$.

Catanese R.

2013. 3D Architectural Videomapping. International Archives of the Photogrammetry, Remote Sensing and Spatial Information Sciences, Volume XL-5/W2,XXIV International CIPA Symposium, 2 - 6 September 2013, Strasbourg, France.

Cluzeau, C.O.

2000. Le Tourisme culturel 2o ed., Paris: Presses Universitaires de France - PUF.

2002. «Le tourisme culturel, un concept pour le XXIème siècle». En D. Vidal (Eds.), Cultura i turisme. Actes del Seminari dut a terme a Barcelona el novembre de 1999, pp. 173-188. Girona: Universitat Girona.

Donaire, J.A.

2002. Les noves tèndencies en el posicionament de la cultura en els escenaris inmediats. En D. Vidal, ed. Cultura i turisme. Actes del Seminari dut a terme a Barcelona el novembre de 1999, pp.111-122. Girona: Universitat Girona.

Duran, P.

2002. La cultura en la promoció turística de les ciutats metropolitanes. En D. Vidal (Ed.), Cultura $i$ turisme. Actes del Seminari dut a terme a Barcelona el novembre de 1999, Girona: Universitat Girona. Fachadas recuperadas en el centro de Málaga. Itinerarios, 2010. Ayuntamiento de Málaga. Recuperado de: http://www.malaga.eu/recursos/economia/vivienda/permanente/Pinturas_murales_Rutas_1_2_3. pdf

García S.

2013. Flujos turísticos en destinos de ciudad. El caso de Málaga. Riuma. Portal Académico. Universidad de Málaga.

Greffe, X.

2002. "Les rapports entre l'offre culturelle et le public touristique: une opportunité pour la culture, le tourisme et l'économie, pp. 55-74". En D. Vidal (Ed.), Cultura i turisme. Actes del Seminari dut a terme a Barcelona el novembre de 1999, Girona: Universitat Girona.

1999. Le tourisme culturel, un concept pour le XX Ième siècle. En D. Vidal (Eds.), Cultura i turisme. Actes del Seminari dut a terme a Barcelona el novembre de 1999, Girona: Universitat Girona: 173-188. 
Guirao Cases F., García Sánchez G., Folgar Batista K., Brotons Giner M., Ledgard Majidi N., Perruca Jaén I.,

2012. Videomapping interactivo. Recuperado de: http://sm.ingenieriamultimedia.org/lib/exe/fetch.php/ memoriaproyeccion.pdf.

López García, I y Navarro Jurado, E.

2007. El patrimonio arqueológico como dinamizador del turismo cultural: actuaciones en la ciudad de Málaga. Baetica, 29: 155-171.

McKercher, B. y Cros, H.D.

2002. Cultural tourism: the partnership between tourism and cultural heritage management, Routledge. Monerés M.

2012. Nuevos instrumentos para la difusión y promoción del turismo cultural. XXXII Reunión de asociaciones y entidades para la defensa del patrimonio cultural y su entorno. Pamplona.

Openstreemaps.

(s.f) Mapa del centro histórico de Málaga (España) en Openstreemaps. Recuperado el 31 Jul. 2017, de: https://www.openstreetmap.org/search?query=M\%C3\%A1laga\#map=17/36.72035/-4.42012.

Prats, Ll.

2011. La viabilidad turística del patrimonio. PASOS. Revista de Turismo y Patrimonio Cultural 9 (2): 249-264.

Richards, G.

2001. Cultural attractions and European tourism, Wallingford: CABI.

2006. "Introduction: Global Trends in Cultural Tourism. pp.1-24". En G. Richards (Ed.), Cultural Tourism: Global and Local Perspectives, Haworth Press Inc.

Romero, J.

2008. Bienes, paisajes e itinerarios. I PH Boletín del Instituto Andaluz del Patrimonio Histórico I, 67 : 30-69. I agosto 2008.

Sust, Xavier.

1975. Las estrellas de la arquitectura. Barcelona. Tusquets. Cuadernos ínfimos 58.

Valero, Estefanía.

2012. Fachadas mediáticas: libro de producción para video mapping sobre una estructura arquitectónica de la ciudad de Caracas. Universidad Católica Andrés Bello. Caracas.

Vidal, D.

2002. "El marc del turisme cultural (pp.21-26)". En D. Vidal (Ed.), Cultura i turisme. Actes del Seminari dut a terme a Barcelona el novembre de 1999, Girona: Universitat Girona.

Weaver B.D, y Oppermann M.

2000. Tourism Management. Australia: John Wiley \& Sons.

Zamudio Vega, L. S.

2012. "La arquitectura en los imaginarios turísticos". RIPS. Revista de Investigaciones Políticas y Sociológicas, vol., 11 (2): 145-158.

\section{Notas}

1 En la página web del museo se puede ampliar la información http://www.tarquinia-cerveteri.it/en/journey-into-the-world-of-the-etruscans.com 